\title{
PHYSICOCHEMICAL CHARACTERIZATION AND MINERALOGICAL EVALUATION OF IRE- EKITI CLAY DEPOSIT IN SOUTHWESTERN NIGERIA
}

\author{
Adekeye Damilola, Popoola Olugbenga, Ibigbami Olayinka, Asaolu Samuel, Olatoye Rauf \\ Department of Chemistry, Ekiti State University Ado-Ekiti, Ekiti State \\ Olumide Abisola \\ Department of Geology, Ekiti State University Ado-Ekiti, Ekiti State \\ Adedotun Ifeoluwa \\ -Department of Pure and Applied Chemistry, Osun State University Osogbo, Osun State
}

\begin{abstract}
Mineralogical evaluation of clay involves the study of clay in terms of their chemical and physical properties. This is done either to identify the type of clay been evaluated or its mineral contents. The present study investigated the physicochemical properties and evaluated the major mineral content of Ire-Ekiti clay. The mineralogical evaluation of the clay and physicochemical characterization of the clay include determination of particle size distribution, surface morphology, $\mathrm{pH}$, moisture content, chemical composition, elemental composition, functional group elucidation, cation exchange capacity, soil organic matter, bulk density and moisture content. Result of the chemical composition determined by the XRF showed that silica $\left(\mathrm{SiO}_{2}\right)$ and alumina $\left(\mathrm{Al}_{2} \mathrm{O}_{3}\right)$ are the major chemical components of the clay with percentage composition of 58.65 and $23.55 \%$ respectively which is a major property of kaolin. In support of the XRF, the PIXE showed that Al $(254444 \mathrm{ppm})$ and $\mathrm{Si}(\mathbf{5 6 8 1 3 8} \mathrm{ppm})$ are the most abundant elements of the clay. The EDX together with the FTIR showed that the metallic constituents of the clay exist in their oxide form which is consistent to the result of the XRF. This study therefore showed that the clay is typically kaolin having kaolinite as its major mineral content.
\end{abstract}

Keywords: Ire-Ekiti; Kaolin; Kaolinite; clay; Mineral analysis; Physicochemical characterization.

\section{INTRODUCTION}

A soil is a complex mixture of different minerals, water, air, organic matter, and remains of decayed organisms (flora, fauna and human) capable of supporting plant and animal life on earth. As a result, soil differs from its parent materials in physical, biological, mechanical and chemical properties
(Seini et al., 2019). Sand, silt, and clay are the particles that make up soil. Sand particles are the largest while clay particles are the smallest (Eric et al., 2014). According to ASTM (2016), clays belong to the family of minerals called phyllosilicates which is made up of tetrahedral silicate sheets and octahedral metal oxide (or hydroxide) sheets with particle size less than $2 \mu \mathrm{m}$. Clay is composed of different minerals and the clay minerals are generally classified into three layer types based upon the number and arrangement of tetrahedral and octahedral sheets in their basic structure. They are 1:1 (e.g. kaolinite), 2:1 (e.g. mica, smectite, and vermiculite groups) and 2:1:1 (e.g. Chlorite) clay minerals (Braddy, 1990). Several techniques have been developed for mineralogical evaluation and identification of different types of minerals present in clay. For instance, X-ray Diffractometry (XRD) among other techniques has been solely used to identify the mineral contents of clay and such is reported in a study by (Akinola et al., 2014). They were able to show that kaolinite, illite and quartz are the clay minerals present in Ishan clay. Recent work by Akinola and Obasi (2014) showed that kaolinite is the major mineral component of kaolin. Some of the most important techniques that have been used for the mineralogical evaluation of clay minerals include scanning electron microscopy (SEM), transmission electron microscopy (TEM), X-ray fluorescence (XRF), Thermogravimetry (TGM), energy dispersive X-ray emission technique (EDX) and proton induced X-ray emission technique (PIXE) (Cook, 2000; Akinola and Obasi, 2014; Sanusi et al., 2016; Awokunmi and Asaolu, 2017; Sanou et al., 2019). Ire-Ekiti a town located in Ekiti State, Southwestern Nigeria has abundant clay deposits. The clay deposits have been mined for several years for its application in pottery, ceramics and architecture. Mineralogical evaluation and physicochemical characterization of this clay is therefore important and has 


\section{International Journal of Engineering Applied Sciences and Technology, 2019 \\ Vol. 4, Issue 8, ISSN No. 2455-2143, Pages 94-99 \\ Published Online December 2019 in IJEAST (http://www.ijeast.com)}

become the aim of this study in order to understand the nature and other possible future application of the clay.

\section{MATERIALS AND METHODS}

\subsection{Study Area}

The study area Ire-Ekiti is a town located between latitude $7^{0}$ $47^{1}$ to $7^{0} 53^{1} \mathrm{~N}$ and longitude $5^{\circ} 18^{\prime} \mathrm{E}$ to $5^{\circ} 24^{\prime} \mathrm{E}$ in Oye local government area of Ekiti State Southwestern Nigeria (Figure 1). The town is known to be the home of Ogun onire whom the Yoruba ethnic group of Nigeria recognizes as the "god of iron". Ire-Ekiti has naturally occurring and abundant clay deposits which are mined for different applications. Ekiti State is located between latitude $7^{0} 20^{1}$ to $8^{0} 00^{1} \mathrm{~N}$ and longitude $4^{\circ} 50^{\prime} \mathrm{E}$ to $5^{\circ} 50^{\prime} \mathrm{E}$.

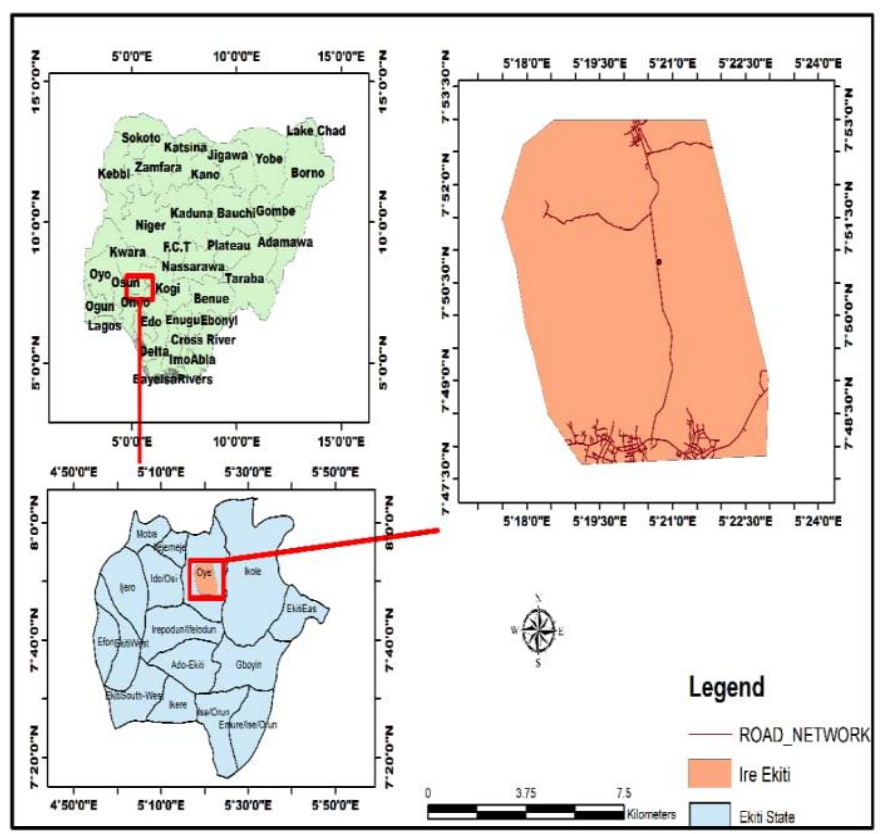

Fig. 1: Geologic map of Nigeria, Ekiti State (showing Oye local government area) and Ire-Ekiti

The State is an upland zone rising over $250 \mathrm{~m}$ above sea level and underlained by different rocks such as the gneisses, granite and charnockite.

\subsection{Sample Collection and Preparation}

Clay soil was collected with the aid of a hand auger from the basement complex of clay deposit in Ire-Ekiti, Southwestern Nigeria. Both surface and subsurface clay samples were collected at four different cardinal points with equidistance of $500 \mathrm{~m}$ way from one another on the trial site. The samples were homogeneously mixed together and an adequate amount for use was taken as the representative sample. None soil sample was separated from the soil sample by hand picking and air dried at room temperature for 72 hours. Thereafter, the clay soil sample was stored in a black polyethylene bag prior to analysis.

\subsection{Physicochemical Characterization}

\subsection{1. pH Determination}

The soil $\mathrm{pH}$ was determined by weighing $10 \mathrm{~g}$ of the clay sample into a $250 \mathrm{ml}$ beaker and $100 \mathrm{~mL}$ deionized water was added to the clay soil sample and stirred for $15 \mathrm{~min}$. The mixture was allowed to settle down for $10 \mathrm{~min}$ (Ramachandra et al., 2012). The $\mathrm{pH}$ was determined by a calibrated $\mathrm{pH}$ meter. This was done by placing the electrode of the $\mathrm{pH}$ meter in the mixture for about 2 minutes to get a stable reading. The stabilized reading was recorded as the $\mathrm{pH}$ level of the sample. The procedure was repeated five times and the mean $\mathrm{pH}$ value was calculated and recorded.

\subsubsection{Cation exchange capacity (CEC)}

The cation exchange capacity of the clay soil samples was determined by methods described by Thorpe (1973). Two gram $(2 \mathrm{~g})$ of air dried clay soil sample was weighed into a $125 \mathrm{ml}$ conical flask and a $100 \mathrm{~mL}$ of $0.5 \mathrm{M} \mathrm{HCl}$ was added to the clay. The flask was shaken for two hours by a rotary orbital shaker and allowed to stand overnight. The sample was filtered and washed with deionized water until the filtrate was free of chloride. The residue was tested with $\mathrm{AgNO}_{3}$ to confirm the presence of chloride. Both the sample and filter paper were transferred into a $250 \mathrm{~mL}$ beaker. $100 \mathrm{~mL}$ of $1.0 \mathrm{M}$ $\mathrm{Ba}(\mathrm{OAc})_{2}$ was added to the beaker and allowed to stand for 2 hours. The sample was filtered and washed with $1.0 \mathrm{M}$ $\mathrm{Ba}(\mathrm{OAc})_{2}$, bringing up the volume to $150 \mathrm{~mL}$. The leachate was titrated to $\mathrm{pH} 7.0$ with $0.5 \mathrm{M} \mathrm{NaOH}$ using thymol blue as an indicator. A blank containing an equivalent volume of 1.0 $\mathrm{M} \mathrm{Ba}(\mathrm{OAc})_{2}$ was also titrated against $0.5 \mathrm{M} \mathrm{NaOH}$ using thymol blue as an indicator. The titration was repeated three times. The CEC of the soil sample was determined according to Equation I.

$\operatorname{CEC}\left(\frac{\mathrm{meq}}{100 \mathrm{~g}}\right)=\frac{(\mathrm{Vs}-\mathrm{Vb}) \times \mathrm{M}}{\text { weight of sample }} \times 100$

Where: $\mathrm{V}_{\mathrm{s}}=$ volume of $\mathrm{NaOH}$ to titrate leachate, $\mathrm{V}_{\mathrm{b}}=$ volume of $\mathrm{NaOH}$ to titrate blank and $\mathrm{M}=$ molarity of $\mathrm{NaOH}$.

\subsubsection{Particle size distribution (PSD)}

The particle size analysis of soil by hydrometer method was conducted according to ASTM D 422 (2007) Standard Test Method to determine the percentage of different particle sizes contained in the soil. The percentage of clay, sand, and silt were determined by taking the reading from the Plot of the grain size curve D versus the adjusted percent finer on the semi logarithmic sheet.

\subsubsection{Soil organic matter $(\mathrm{OM})$}

The soil organic matter was determined by method of lost on ignition (LOI) Heiri et al. (2001) with little modification. Five 


\section{International Journal of Engineering Applied Sciences and Technology, 2019 \\ Vol. 4, Issue 8, ISSN No. 2455-2143, Pages 94-99 \\ Published Online December 2019 in IJEAST (http://www.ijeast.com)}

gram $(5 \mathrm{~g})$ of the dry raw clay sample was weighed into a 0.03 clean and dry empty crucible (which has been preheated at the temperature of $500{ }^{\circ} \mathrm{C}$ ) of a known weight. The clay sample was heated in a furnace at the temperature of $500{ }^{\circ} \mathrm{C}$ for 8 hours, then removed, cooled in a desiccator and weighed until a constant weight was obtained. The difference in weight between the heated clay and the raw clay divided by the weight of the raw clay then multiplied by 100 gave the per cent organic matter content of the soil.

\subsubsection{Moisture content determination (MC)}

$10 \mathrm{~g}$ of the raw clay soil sample was dried in an air drying oven at the temperature of $105^{\circ} \mathrm{C}$ for 24 hours (AOAC 1990). The final weight of the dried sample was recorded. The percentage moisture content was calculated by Equation II.

$\% \mathrm{MC}=\frac{W i-W f}{W i} \times 100$

Where $W i$ and $W f$ are weight of the clay sample before and after drying respectively while $M C$ is moisture content of the garden egg.

\subsubsection{Bulk density}

The bulk density of the clay soil was determined by weighing a proportion of the sample into a dry clean aluminum cylinder cup. The soil sample was dried to a constant weight for $24 \mathrm{hrs}$ in an air drying oven at temperature of $105^{\circ} \mathrm{C}$. The weights of the dried samples were taken again after drying and the volume of the cylinder was calculated. The bulk density of the soil was evaluated using Equation III.

Bulk density $\left(\frac{\mathrm{g}}{\mathrm{ml}}\right)=\frac{\text { Mass of clay soil }}{\text { volume of cup }}$

\subsection{Mineralogical Evaluation}

The functional group elucidation of the clay soil was carried out by Fourier Transformed Infrared Spectrophotometer (FTIR). Scanning Electron Microscope (SEM) was used to show surface morphology of the clay soil and its pore diameter. Elemental composition and concentration (ppm) was determined by proton induce X-ray emission technique (PIXE). Energy Dispersive X-ray Emission (EDX) technique was used to measure the carbon content of the soil sample and to obtain information on the major elemental composition of the clay soil in percentage by weight. Chemical composition of the clay was determined by X-ray fluorescence spectroscopy (XRF).

\section{RESULTS AND DISCUSSION}

\subsection{Physicochemical Properties of the Clay Soil}

Table 1: Physicochemical Properties of the Clay Soil

\begin{tabular}{c|c|c|c|c|c}
\hline pH & $\begin{array}{c}\text { CEC } \\
(\mathbf{m e q} / \mathbf{1 0 0 g})\end{array}$ & $\begin{array}{l}\text { SOM } \\
(\boldsymbol{\%})\end{array}$ & $\begin{array}{l}\text { PSD } \\
(\boldsymbol{\%})\end{array}$ & $\begin{array}{l}\text { MC } \\
(\boldsymbol{\%})\end{array}$ & $\begin{array}{l}\text { Bulk density } \\
(\mathbf{g} / \mathbf{m L})\end{array}$ \\
\hline $6.12 \pm$ & $8.76 \pm$ & $9.25 \pm$ & Clay $=$ & & 1.15 \\
\hline
\end{tabular}




\section{International Journal of Engineering Applied Sciences and Technology, 2019 \\ Vol. 4, Issue 8, ISSN No. 2455-2143, Pages 94-99 \\ Published Online December 2019 in IJEAST (http://www.ijeast.com)}

This shows that the clay is kaolin. It has been shown by some researchers that kaolin consisting majorly of kaolinite mineral is often characterized by higher percentage of Silica $\left(\mathrm{SiO}_{2}\right)$ and alumina $\left(\mathrm{Al}_{2} \mathrm{O}_{3}\right)$ than other chemical components (Eric et al., 2014; Mbaye et al., 2014; Awokunmi and Asaolu, 2017). The presence of $\mathrm{Fe}_{2} \mathrm{O}_{3}, \mathrm{CaO}$ and $\mathrm{MgO}$ alongside the $\mathrm{SiO}_{2}$ and $\mathrm{Al}_{2} \mathrm{O}_{3}$ in the clay soil is indicative of a pozzolana property for possible application as a cementing material or alternative cement.

\subsubsection{Elemental Composition}

The elemental composition of the clay soil was elucidated by PIXE analysis (Table 3). The result from the PIXE showed that $\mathrm{Al}$ and $\mathrm{Si}$ are the major elemental constituents of the clay soil. The relative abundance of the $\mathrm{Al}(254444 \mathrm{ppm})$ and $\mathrm{Si}$ (568138 ppm) as shown by the PIXE complements the results of the XRF and confirming the alumino-silicate nature of the clay which is typical of kaolin.

Table 2: Elemental composition and concentration of raw Ire-Ekiti clay soil

\begin{tabular}{l|l|r}
\hline Atomic no. & Symbol & Conc (ppm) \\
\hline 11 & $\mathrm{Na}$ & 27510 \\
\hline 12 & $\mathrm{Mg}$ & 155101 \\
\hline 13 & $\mathrm{Al}$ & 254444 \\
\hline 14 & $\mathrm{Si}$ & 568138 \\
\hline 15 & $\mathrm{P}$ & 330 \\
\hline 17 & $\mathrm{Cl}$ & 281 \\
\hline 19 & $\mathrm{~K}$ & 2820 \\
\hline 20 & $\mathrm{Ca}$ & 2723 \\
\hline 22 & $\mathrm{Ti}$ & 2097 \\
\hline 24 & $\mathrm{Cr}$ & 261 \\
\hline 25 & $\mathrm{Mn}$ & 312 \\
\hline 26 & $\mathrm{Fe}$ & 41520 \\
\hline 29 & $\mathrm{Cu}$ & 381 \\
\hline 30 & $\mathrm{Zn}$ & 155 \\
\hline 37 & $\mathrm{Rb}$ & 35.8 \\
\hline 40 & $\mathrm{Zr}$ & 562 \\
\hline 47 & $\mathrm{Pd}$ & 20.5 \\
\hline 48 & $\mathrm{Ag}$ & 210 \\
\hline 50 & $\mathrm{Cd}$ & 90.5 \\
\hline 82 & $\mathrm{Sn}$ & 10.8 \\
\hline & $\mathrm{Pb}$ & \\
\hline & & \\
\hline
\end{tabular}

The presence of exchangeable ions such as $\mathrm{Ca}$ (2723), $\mathrm{Cl}$ (281) Mg (155101), Na (27510), Fe (41520), Cu (381), Zn (155) and K (2820) showed an adsorbent property of the clay for potential remediation of metals and none metals from their contaminated medium by ion exchange mechanism. The clay soil could therefore be potentially applied in adsorption technology as suggested by Awokunmi and Asaolu (2017) and Adekeye et al. (2019).

\subsubsection{Surface Morphology}

The SEM micrograph presents a microporous structure, relative abundance and size of the pores on the surfaces of the kaolin as well as the pore diameter $(10 \mu \mathrm{m})$ (Figure 2).

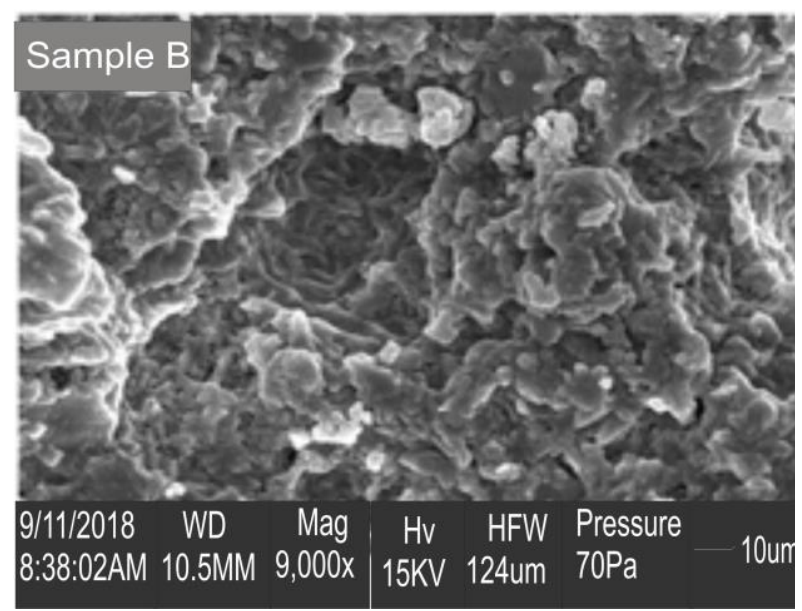

Fig 2: SEM image showing surface morphology of the Ire-Ekiti Clay soil

The SEM image showed a very dense stacking and continuous piling of particles upon one another forming a tangled network. The surfaces are rough with microporous structure like honeycomb.

\subsubsection{Functional group elucidation}

The functional groups present in the clay soil were shown by FTIR analysis (Figure 3 ). The result of the FTIR analysis of the raw clay is shown in Figure 4.3 respectively. The FTIR results showed adsorption bands at $3697,3620 \mathrm{~cm}^{-1}$, which are due to the presence of $\mathrm{NH}$ group. The $\mathrm{NH}$ group may be present in the clay soil as result of decayed organic matter. The bands observed at 3421 and $3263 \mathrm{~cm}^{-1}$ are due to $\mathrm{OH}$ group of either bonded or coordinated water in the clay soil. The weak absorption band at $1635 \mathrm{~cm}^{-1}$ arises as a result of $\mathrm{C}$ $\mathrm{H}$ group present in the soil. The $\mathrm{CN}$ triple bond in the soil is shown by the absorption band at $2351 \mathrm{~cm}^{-1}$. It is typical of a clay soil (kaolin) to show absorption band corresponding to the presence of $\mathrm{Si}-\mathrm{O}-\mathrm{Si}$ and $\mathrm{Si}-\mathrm{O}-\mathrm{Al}$ group.

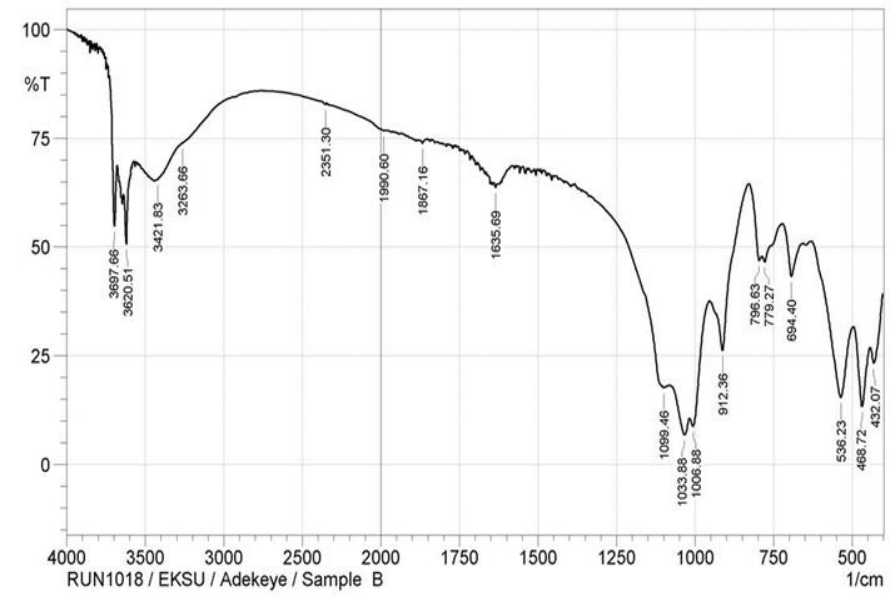

Fig.3: FTIR Spectra of the Ire-Ekiti clay soil 


\section{International Journal of Engineering Applied Sciences and Technology, 2019 \\ Vol. 4, Issue 8, ISSN No. 2455-2143, Pages 94-99 \\ Published Online December 2019 in IJEAST (http://www.ijeast.com)}

The absorption bands at 1099 and $1006 \mathrm{~cm}^{-1}$ correspond to Si$\mathrm{O}-\mathrm{Si}$ group present in the clay which is confirmed by the band at $694 \mathrm{~cm}^{-1}$ that showed the bending mode of the same group; while the presence of metallic oxide in the clay soil is indicated by the intensity bands at 468 and $432 \mathrm{~cm}^{-1}$. The result of the FTIR analysis is consistence with the results from the XRF analysis by confirming the presence of metallic oxide in the clay soil.

\subsubsection{EDX analysis}

The presence and relative abundance ( $\mathrm{w} \%$ ) of Aluminum (Al) and Silicon ( $\mathrm{Si}$ ) compared to other elemental components of the clay soil was also confirmed by the EDX analysis (Figure 4 and Table 3 ).

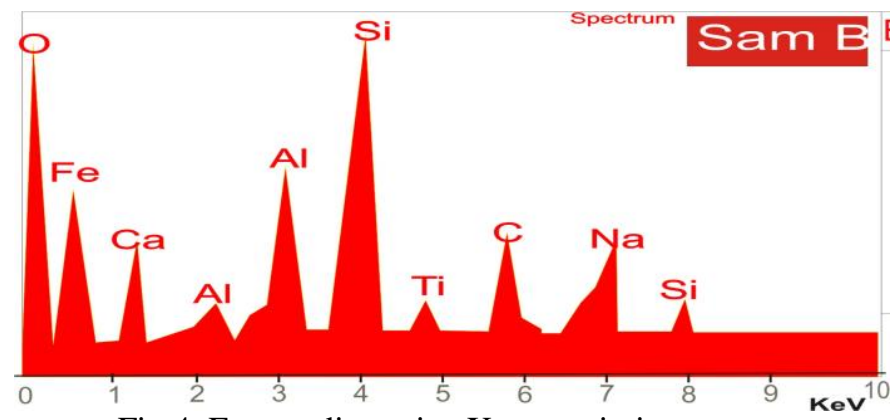

Fig 4: Energy dispersive X-ray emission spectra

Table 3: percentage by weight of the elemental composition of the clay

\begin{tabular}{c|c}
\hline Element & Wt (\%) \\
\hline $\mathrm{C}$ & 4.45 \\
\hline $\mathrm{O}$ & 16.20 \\
\hline $\mathrm{Na}$ & 3.60 \\
\hline $\mathrm{Ti}$ & 1.52 \\
\hline $\mathrm{Si}$ & 53.00 \\
\hline $\mathrm{Ca}$ & 0.74 \\
\hline $\mathrm{Al}$ & 18.15 \\
\hline $\mathrm{Fe}$ & 3.86 \\
\hline
\end{tabular}

The result from EDX (Figure 4) showed that Silicon, Aluminum and oxygen are the major elemental composition and possessing the highest percentage by weight $(18.15,16.20$ and $53.00 \mathrm{w} \%$ respectively) of the raw clay soil. The presence of oxygen and absence of hydrogen is an indication that the elements could be present in their oxide form rather than hydroxide also supporting the results of the FTIR and PIXE and XRF. In consistency to other techniques that have been applied for mineralogical evaluation Ire-Ekiti clay soil in the present study, the EDX also showed the presence of some important exchangeable cations such as $\mathrm{Na}(3.70 \mathrm{w} \%), \mathrm{Ca}$
$(0.74 \mathrm{w} \%)$ and $\mathrm{Fe}(3.86 \mathrm{w} \%)$. The relative abundance (percentage by weight) of $\mathrm{Si}$ and $\mathrm{Al}$ compared to other elements showed that the clay soil is typically Kaolin confirming the results of the PIXE and XRF analysis.

\section{CONCLUSION}

Ire-Ekiti clay soil has been characterized by some suitable techniques order than XRD to evaluate the major mineralogical content of the clay for proper classification. The results from the techniques used in this study are consistent to one another. The results showed that kaolinite is the major clay mineral in the clay, indicating that the clay is typically kaolin. Also, the Ire-Ekiti kaolin showed properties that indicated its potentials to be used as a pozzolana and industrial adsorbent for remediation of contaminants in wastewater. The results from this research therefore become an added value to existing data and information on mineralogical and physicochemical evaluation of clay soil and potential application of Ire-Ekiti clay soil.

\section{REFERENCES}

1. Adekeye, D.K., Asaolu, S.S., Adefemi, S.O and Ibigbami O.A. (2019). Heavy Metal Adsorption Properties of the Basement Complex of Clay Deposit in Ire-Ekiti south western Nigeria. IOSR-JESFT. 2019; 13 (2): 01-08

2. Akinola, O and Obasi, O.R (2014) A Compositional Characteristics And Industrial Potential of The Lateritic Clay Deposit In Ara-Ijero Ekiti Areas, Southwestern Nigeria. International Journal Of Scientific \& Technology Research 3 (8), pp: 304-311

3. Akinola, Oluwatoyin.O, Ademilua and Oladimeji. L (2014) Compositional Features and Functional Industrial Applications of the Lateritic Clay Deposits in Oye-Ekiti and Environs, Southwestern Nigeria The International Journal Of Science \& Technoledge 2 (9); pp: 6-12.

4. AOAC (1990). Official methods of analysis. Washington: Association of Official Analytical Chemists.

5. ASTM C150/C150M-16, Standard Specification for Portland Cement. West Conshohocken, Pa.: ASTM International, 2016.

6. ASTM D 422 (2007) Standard Test Method for particle size analysis of soil. ASTM international West Conshohocken, PA.

7. Awokunmi, E.E and Asaolu, S.S. (2017). Physicochemical and performance evaluation of natural and modified Ire-Ekiti clay: Emerging substrate in the de-fluoridation of drinking water. Journal of physical and chemical sciences 5: 23483270 


\section{International Journal of Engineering Applied Sciences and Technology, 2019 \\ Vol. 4, Issue 8, ISSN No. 2455-2143, Pages 94-99 \\ Published Online December 2019 in IJEAST (http://www.ijeast.com)}

8. Brady, N. (1990) Soil Colloids : Their Nature and Practical Significance. The Nature and Properties of Soils, 10th Ed.; Macmillan Publishing Co.: New York; 177-212.

9. Cook, N.J., 2000: Mineral characterisation of industrial minerals deposits at the Geological Survey of Norway: a short introduction. Norges geologiske undersøkelse Bulletin, 436, 189-192.

10. Eric, O.A., Mark, B, and Kankam, C. K. (2014). Influence of calcined clay pozzolana on strength characteristics of Portland cement concrete International Journal of Materials Science and Applications 3(6): 410-419

11. Heiri, O., Lotter, A., and Lemcke, G. (2001). Loss on ignition as a method for estimating organic and carbonate content in Journal of Paleolimnology, 25: 101-110.

12. Mbaye, A., Diop, C. A.., MieheBrendle, K Jocelyne, S. F and Maury. T. 2014. Characterization of natural and chemically modified kaolinite from Mako (Senegal) to remove lead from aqueous solutions. Clay Minerals, 49 :527-539.

13. Ramachandra, T.V, SubashChandran, M.D, Joshi, N.V, Rajinikanth, R and Raushan, K. (2012).Water, soil and sediment characterization: Sharavathiriver basin, Western Gaths, ENVIS Technical report : 21, Energy and Wetlands Research Group, Center for Ecological Sciences, India Institute of Science, Bangalore 560012.

14. Sanou, I., Sawadogo, M., Seynou, M., Zerbo, L. and Ouedraogo, R. (2019) Study of the Mechanical Behaviour of Mortars Modified with Rice Husk Ash. Journal of Minerals and Materials Characterization and Engineering, 7, 373-384.

15. Sanusi, K.A, Mar, B.A and Sani I.M (2016) Evaluation of the Application of Carica papaya Seed Modifed Feldspar Clay for Adsorption of $\mathrm{Pb}^{+2}$ and $\mathrm{Cu}^{+2}$ in Aqueous Media: Equilibrium and Thermodynamic studies. J Environ Anal Toxicol 6: 351. doi:10.4172/2161-0525.1000351

16. Seini, A.S., Oparaku, L.A. and Itodo I.N. (2019) Physico-Chemical and Mechanical Properties of Soils of Owukpa Lower Coal Measure Geological Formation of Anambra Basin-Nigeria International Journal of Engineering and Advanced Technology (IJEAT); pg: 1-5

17. Thorpe, V.A. (1973). Collaborative study of the cation exchange capacity of peat minerals. Journal of the AOAC, 56: 154-156

18. Unuabonah E.I and Adebowale, K.O. (2009), Optimization of kinetic data for two-stage batch adsorption of $\mathrm{Pb}(\mathrm{II})$ ions onto tripolyphosphatemodified kaolinite clay, J. Chem. Technol. Biotechnol. 84: 1726-1735. 